\title{
The JDE's Peer Education: Reviews of the Literature (PERLs)
}

\author{
Marita R. Inglehart, Dr phil habil
}

$\mathrm{T}$ This issue of the Journal of Dental Education includes the third set of Peer Education: Reviews of the Literature (PERLs), a new section introduced in January 2015. Its purpose is to call attention to research published in other journals that has particular relevance to dental education. Our scope of interest includes, but is not limited to, other educational journals in the health professions such as the European Journal of Dental Education, Nursing Education Today, and Academic Medicine. We are not the only journal to use its own pages this way; many of us, for example, enjoy reading Dr. Bruce Pihlstrom's "Journal Scan" in the Journal of the American Dental Association. However, the PERLs differ from others in two main ways.

First, our section is topic-driven. We ask authors of each set of PERLs to select a topic of interest and to write short reviews of relevant articles in other fields that offer insights into this topic. For example, the January 2015 PERLs focused on interprofessional education (IPE). The five reviews informed readers about the value of the Triple Aim approach to study IPE outcomes, faculty development IPE programs, student responses to IPE, and an innovative IPE program designed to address health care needs of women transitioning from prison to community reentry. The April 2015 PERLs addressed the topic of blended learning, discussing research about engaging students in blended learning, its weaknesses and strengths, and students' responses. The PERLs in this issue focus on the use of portfolios in educating health professions students and include research done in dental hygiene, medicine, nursing, pharmacy, and public health programs. We hope our topic-based focus will thus also serve to provide an easily accessible, quick overview of recent research on the subject for educators, whether for use in their teaching or their own research.

A second way in which the JDE reviews differ from those in other journals is that every set of PERLs is developed and written by students or residents at an academic dental institution, under the guidance of a faculty member. We chose this method partly to engage more students in our journal's work. Even more importantly, our hope is that preparing the PERLs will encourage these students to think more critically about their education as they learn about educational research being done across the health professions. In addition to driving their learning, we hope it broadens their thinking about one aspect of academic careers. Despite recent decreases in the number of vacant budgeted faculty positions, concerns about faculty shortages persist, ${ }^{1}$ and a major contributing factor is the small number of graduates interested in academic careers. We hope that challenging faculty members to collaborate with their students to identify a topic of interest, select articles, and report on their value can encourage students to begin their own research and publishing careers, as well as encourage other students to get involved.

Finally, with the PERLs section, we help to implement one of the core principles of IPE: the idea that educators and students in each individual health profession can benefit from learning about others. Expanding the horizons of the student authors and our journal's readers in this way serves both our journal's purpose and academic dentistry as a whole.

\section{REFERENCE}

1. Garrison GE, McAllister DE, Anderson EL, Valachovic RW. Dental school vacant budgeted faculty positions, academic years 2008-09 and 2010-11. J Dent Educ 2014;78(4):638-47.

Dr. Inglehart is Associate Editor of the JDE and Professor, Department of Periodontics and Oral Medicine, School of Dentistry and Adjunct Professor, Department of Psychology, College of Literature, Science, and Arts, University of Michigan; mri@ umich.edu. Faculty members, students, or residents interested in organizing a PERLs section should contact her with their ideas. 